\title{
Autochthonous case of Canine Visceral Leishmaniasis and presence of sand flies in a high altitude area
}

\author{
Caso autóctone de Leishmaniose Visceral Canina e \\ presença de flebotomíneos em área de elevada altitude
}

\author{
Carlos Roberto Cruz Ubirajara Filho ${ }^{1 *}$ (D), Carlos Alberto do Nascimento Ramos ${ }^{2}$ (D), Alessio Giannelli ${ }^{3}$ (D), \\ Leucio Câmara Alves ${ }^{4}$ (D), Gílcia Aparecida de Carvalho ${ }^{1}$, Rafael Antonio Nascimento Ramos ${ }^{1}$
}

\begin{abstract}
Visceral leishmaniasis (VL) is a disease that affects dogs. The aim of this study was to describe an autochthonous case of VL and to report the presence of sand flies in a high-altitude area of Northeastern Brazil. In February 2019, a sampling was performed of a suspected animal $(\mathrm{n}=1)$, and the presence of sand flies was investigated using CDC light traps. The dog scored positive for Leishmania infantum, and four specimens of sand flies were captured and classified as Lutzomyia evandroi. This study detected the first autochthonous case of canine visceral leishmaniasis (CVL) in an area of high altitude were only L. evandroi has been collected.
\end{abstract}

KEYWORDS: Dog; Zoonosis; Leishmania; Lutzomyia

RESUMO: Leishmaniose visceral (LV) é uma doença que afeta cães. O objetivo deste estudo foi avaliar a ocorrência de LV e a presença de flebotomíneos em uma área de alta altitude no Nordeste do Brasil e discutir os achados com base na perspectiva de Saúde Única. Em fevereiro de 2019, foi realizada uma amostragem de um animal suspeito $(\mathrm{n}=1)$, e a presença de flebotomíneos foi investigada usando armadilhas luminosas do tipo CDC, os flebotomíneos foram coletados e identificados morfologicamente, foram coletadas um total de 4 amostras. O cão obteve resultado positivo para Leishmania infantum e os quatro espécimes coletados foram classificados como Lutzomyia evandroi. Os achados deste estudo servem de alerta para o serviço de saúde e médicos veterinários da região quanto à presença de cães infectados por $L$. infantum e seus supostos vetores, em nova área de ocorrência de Leishmaniose Visceral.

PALAVRAS-CHAVE: Cão; Zoonoses; Leishmania; Lutzomyia

\section{INTRODUCTION}

Leishmaniasis is considered a tropical neglected disease widely spread throughout the world, with a great relevance in public health. According to the World Health Organization (WHO), about 350 million people are at risk of infection, and approximately two million of new cases occur every year (WHO, 2019). Amongst the different clinical pictures presented by this disease, visceral leishmaniasis (VL) has been considered potentially fatal when unproperly treated. Clinically, VL is featured by hepatomegaly, splenomegaly, severe anaemia, fever, diarrheal, anorexia, and eventually death (MEDINA-COLORADO et al., 2017).

In Brazil, VL is caused by the trypanosomatid protozoa of the species Leishmania (Leishmania) infantum, which is transmitted by sand flies of the genus Lutzomyia (SALES et al., 2019). Although the species Lutzomyia longipalpis had been considered as the most epidemiologically important, there is currently evidence of other putative vector species (e.g., Lutzomyia evandroi, Lutzomyia cruzi and Lutzomyia migonei) (CARVALHO et al., 2007; SHERLOCK, 1996; UBIRAJARA FILHO et al., 2020). VL is considered a rural disease, with complex epidemiological chain involving wildlife as definitive vertebrate hosts (e.g., opossums and wild carnivores). However, over the last decades it has been observed a spread of cases from rural to urban areas (DANTAS-TORRES and BRANDÁO-FILHO, 2006), with a reorganization of the cycle, now involving domestic animals, including dogs.

After this phenomenon, referred as to "urbanization of the VL", domestic dogs have been considered the main urban reservoir

'Universidade Federal do Agreste de Pernambuco - Garanhuns (PE), Brazi

${ }^{2}$ Faculdade de Medicina Veterinária e Zootecnia, Universidade Federal do Mato Grosso do Sul - Campo Grande (MS), Brazil.

${ }^{3}$ Poulpharm BVBA - Izegem, Belgium.

${ }^{4}$ Universidade Federal Rural de Pernambuco - Recife (PE), Brazil.

*Corresponding author: carlosubirajarafilho_vert@hotmail.com

Conflict of interest: On behalf of all authors, the corresponding author states that there is no conflict of interest.

Received: 04/30/2020. Accepted: 07/07/2020 
of the infection (PIMENTEL et al., 2015). Several efforts have been made by the Brazilian Health Service to reduce the spreading of $\mathrm{VL}$ in urban areas, including the questionable dog culling. However, these measures proved to be insufficient, as confirmed by the increase in the number of cases throughout the country. In the state of Pernambuco, for instance, a clear expansion of VL cases have been registered since 1990s (DANTAS-TORRES and BRANDÁO-FILHO, 2006), and nowadays animal and human cases are documented in areas where the disease were considered absent. The municipality of Garanhuns represents an example as until now there is only serological evidence of the infection in dogs (LINS et al., 2018), and human cases were considered inexistent until 2012. This are has a high average altitude, important feature to reduce the diversity and abundance of sand flies species (YARED et al., 2017).

Therefore, the aim of this study was to describe the first autochthonous case of Canine Visceral Leishmaniasis (CVL) and to provide evidence of the presence of sand flies in a high altitude area.

\section{MATERIAL AND METHODS}

In February 2019, a 3 years old female Labrador retriever presented clinical signs potentially related to leishmaniasis. The dog lived in a cattle farm, located in the peri-urban area of the municipality of Garanhuns (Latitude 08 $53^{\prime 2} 25^{\prime \prime}$ and Longitude 36 29'34'), state of Pernambuco, northeastern region of Brazil. The dog's parents born in the same place and never moved to areas outside the farm. In addition, they did not present clinical signs related to CVL.

The farm where the animal lived was destined to milk bovine production, and the presence of organic matter (e.g., leaves and animal waste) was noticed in abundance. This area is featured by a high altitude [896 meters above sea level (a.s.l.)], and present an annual temperature mean of $20^{\circ} \mathrm{C}$ and relative humidity of $90 \%$.

Upon the physical examination, the animal revealed areas of alopecia, furfur dermatitis, anorexia and weight loss. The animal was born in the farm and had never moved to leishmaniasis endemic areas. The owner mentioned that in 2016, another $\mathrm{dog}$ frequently travelling onto an endemic area (i.e., Tamandaré beach) lived in the farm and was diagnosed with VL.

A blood sample was collected through the cephalic venepuncture and the material stored in tubes with ethylenediamine-tetra-acetic acid (EDTA) anticoagulant. In addition, a skin scraping and a bone marrow puncture were performed for microscopical and molecular analyses.

Blood was tested using the immunochromatography technique (TR-DPP BioManguinhos ${ }^{\circledR}$ ) following the manufacturer's instructions. The cytological examinations of the skin and of the bone marrow were carried out after staining slides using the rapid panoptic method (RenyLab ${ }^{\odot}$ ), and then they were observed under an optical microscope ( $40 \mathrm{x}$ and $100 \mathrm{x}$ ). Photomicrographs were acquired using a digital camera (CMOS-5.0) mounted directly on the microscope (New Optics NO 226). The software TCapture 4.3 was used for the image acquisition and measurements of parasitic structures.
For molecular analysis, genomic DNA was extracted from the bone marrow using a commercial kit (Wizard ${ }^{\circ}$ Genomic DNA Purification Kit, Promega, USA) in accordance with the manufacturer's instructions. Afterward, the sample was subjected to PCR reaction with primers MC1 5'-GTTAGC CGATGGTGGTCTTG-3' and MC2 5'-CACCCATTTTTCCGATTTTG-3' (CORTES et al., 2004), which delimit a DNA fragment of approximately 447 $b p$ of the kinetoplast minicircle. The amplifications were visualized after $2 \%$ agarose gel electrophoresis in UV transilluminator. Then, the amplified fragments were purified using ExoSAP-IT PCR Product Cleanup Reagent (Applied Biosystems by Thermo Fisher Scientific - BR) and sequenced in both directions using the Sanger method in automatic sequencer ABI 3130 (Applied Biosystems). The chromatograms were analysed using BioEdit v.7.2.5 software and consensus sequences were submitted to BLASTn search (ALTSCHUL et al., 1990) to determine the sequence identity, based on comparisons with DNA sequences available in the GenBank database.

In order to detect the presence of sand flies in the study area, a sampling session was performed soon after the confirmation of the infection. Briefly, CDC light traps $(n=5)$ were installed $1.5 \mathrm{~m}$ above ground level at night $(5 \mathrm{pm})$ and collected at dawn ( $6 \mathrm{am})$ (UBIRAJARA FILHO et al., 2020). The traps were distributed over three consecutive nights, placed near animals and vegetated areas. Specimens collected were stored in plastic tubes containing $70 \%$ alcohol, and afterwards morphologically identified using dichotomous keys (SHIMABUKURO et al., 2017). During the three nights of collection, a minimum temperature of $19^{\circ} \mathrm{C}$ and maximum of $33^{\circ} \mathrm{C}$ were registered, whereas the relative humidity ranged from $40 \%$ to $95 \%$.

The Ethical Committee of Animal Experimentation of the Universidade Federal Rural de Pernambuco approved all procedures herein performed (license number 120/2018).

\section{RESULTS AND DISCUSSION}

The dog scored reagent at the immunochromatography test and amastigote forms of Leishmania spp. were detected at microscopic examination of the bone marrow and skin scrapping. The amastigote forms were characterized by internal flagella, mean length of $3.8 \mu \mathrm{m}( \pm 4 \mu \mathrm{m})$ and mean width of $2.4 \mu \mathrm{m}$ $( \pm 2.5 \mu \mathrm{m})$ (Fig. 1). At molecular analysis (PCR and DNA sequencing) identity higher than $99 \%$ was observed with $L$. infantum DNA sequence available from Genbank (MT066190). The sequence obtained in the present study was deposited in GenBank under the access number MN173813.

Four phlebotomine sand flies (three male and one female) were captured and classified as Lutzomyia evandroi (Fig. 2).

This study provides the first autochthonous case of CVL supported by the collection of sand flies in a high-altitude area of Northeastern Brazil potentially serving as vectors.

All diagnostic tools herein employed (i.e., serological, microscopical and molecular analyses) allow a safe detection 
of $L$. infantum infection in a dog. Accordingly, it is indisputable the prone role of this animal as reservoir of the protozoa; therefore this finding deserves a great attention since the area had been considered free for Leishmania infection in dogs, and until only serological evidence existed (LINS et al., 2018). Clinically, the animal exhibited dermatopathies that has been one of the most common finding in dogs with VL. It is known that dogs host a high concentration of amastigote forms in the skin, making them the main reservoir of the parasite in urban areas (SALES et al., 2015).

After the confirmation infection, it should be demonstrated whether the vector of $L$. infantum is present in the studied area. The identification of $L u$. evandroi sand flies in this region should raise the question about its vector role for

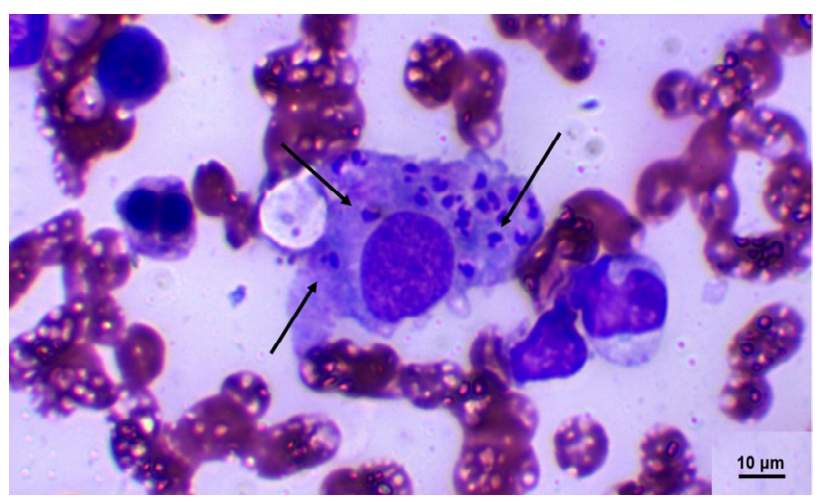

Figure 1. Amastigote forms of Leishmania spp. in bone marrow smear (scale-bar $=10 \mu \mathrm{m})$.

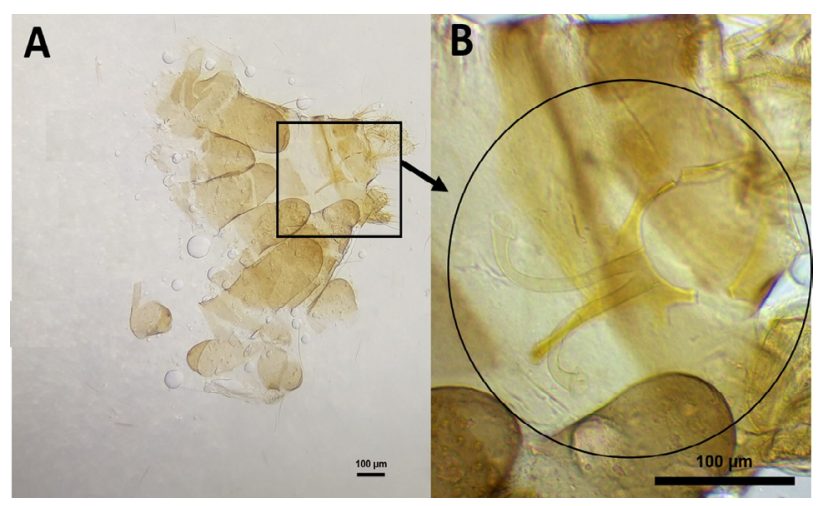

Figure 2. Lutzomyia evandroi female, A - posterior follow-up of female abdomen, black square, B - spermatheca spherical, characteristic of the species, black circle, (scale-bar $=100 \mu \mathrm{m})$.
L. infantum. Indeed, although for a long time, Lu. longipalpis had been regarded as the only vector of $L$. infantum in Brazil (SHERLOCK, 1996), the putative role of other species such as Lu. migonei, Lu. cruzi and Lu. evandroi (CARVALHO et al., 2007; SHERLOCK, 1996; UBIRAJARA FILHO et al., 2020) has been debated. The retrieval of a single species (i.e., Lu. evandroi) of sand fly does not exclude the existence of others more epidemiologically important such as Lu. longipalpis, especially because both species share the same occurrence area (SHERLOCK, 1996). However, a recent study in which sand flies collections were performed for a one-year period detected only the presence of $L u$. evandro $i$ in this same area were the dog was diagnosed (UBIRAJARA FILHO et al., 2020). There are reports of $L u$. evandroi in high altitude areas, however it is usually found together with other species (SALES et al., 2019), different from what occurred in this study.

From an epidemiological perspective, the detection of an infected $\operatorname{dog}$ and the presence of sand flies follow a scenario frequently observed over the time in Brazil, where the spreading of VL has been a common finding. Northeastern Brazil is traditionally endemic for VL, with reservoirs, humans and vectors sharing the same ecological niche that contribute to the persistence of the Leishmania life cycle (PIMENTEL et al., 2015). Information about the ecological situation of this case deserves to be remarked, as sand flies were collected at a high altitude (i.e., $896 \mathrm{~m}$ a.s.l.). It has been demonstrated that the diversity and abundance of sand flies species is indirectly collected with the increases in the altitude, but they may be detect in areas presenting 2300 meters a.s.l. (YARED et al., 2017). It is known that these invertebrates are able to adapt to different conditions being found in inospt areas. It is worth mentioning that the risk of Leishmania transmission increases when sand flies adapt to new environments and new conditions, allowing to colonize areas considered sand flies free (SALES et al., 2015).

\section{CONCLUSION}

In conclusion, this study detected the first autochthonous case CVL in an area of high altitude were only $L$. evandroi has been collected. This finding confirms the spreading of CVL for areas where the disease was considered absent; in addition the retrieval of only $L u$. evandroi open new possibilities to better assess the role of this sand fly species as potential vector of $L$. infantum.

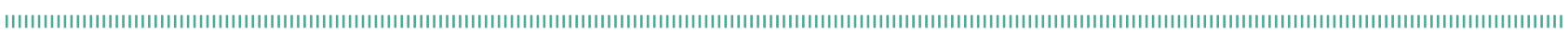
REFERENCES

ALTSCHUL, S. F. et al. Basic alignment search tools. Journal of Molecular Biology, v.215, p.403-410, 1990.

CARVALHO, M. R. et al. Phlebotomine sandfly species from an American visceral leishmaniasis area in the Northern Rainforest region of Pernambuco State, Brazil. Caderno de Saúde Pública, v.23, n.5, p. $1127-1232,2007$.

CORTES, S. et al. PCR as a rapid and sensitive tool in the diagnosis of human and canine leishmaniasis using Leishmania donovani 
s.l.-specific kinetoplastid primers. Transactions of the Royal Society of Tropical Medicine and Hygiene, v.98, n.1, p.1217, 2004.

DANTAS-TORRES, F.; BRANDÃO-FILHO, S. P. Expansão Geográfica da Leishmaniose Visceral no Estado de Pernambuco. Revista da Sociedade Brasileira de Medicina Tropical, v.39, n.4, p.352-356, 2006.

LINS, T. N. B. et al. Seroprevalence and spatial distribution of canine leishmaniasis in an endemic region in Brazil: how has the situation changed after 10 years?. Revista da Sociedade Brasileira de Medicina Tropical, v.51, n.5, p.680-682, 2018.

MEDINA-COLORADO, A. A. et al. Splenic CD4+ T Cells in progressive visceral leishmaniasis show a mixed effectorregulatory phenotype and impair macrophage effector function through inhibitory receptor expression. PLoS One, v. 12, n. 1, p.e0169496, 2017.

PIMENTEL, D. S. et al. Prevalence of zoonotic visceral leishmaniasis in dogs in an endemic area of Brazil. Revista da Sociedade Brasileira de Medicina Tropical, v.48, n.4, p.491-493, 2015.

SALES, K. G. S. et al. Home sweet home: sand flies find a refuge in remote indigenous villages in north-eastern Brazil, where leishmaniasis is endemic. Parasites \& Vectors, v.12, n. 118 , p. 1-12, 2019.
SALES, K. G. S. et al. Identification of phlebotomine sand fly blood meals by real-time PCR. Parasites \& Vectors, v.8, p. 1-6, 2015.

SHERLOCK, I. A. Ecological interactions of visceral leishmaniasis in the State of Bahia, Brazil. Memórias do Instituto Oswaldo Cruz, v.91, p.671-683, 1996.

SHIMABUKURO, P. H. F. et al. Checklist of American sand flies (Diptera, Psychodidae, Phlebotominae): genera, species, and their distribution. ZooKeys, v. 660, p. 67-106, 2017.

SISTEMA NACIONAL DE AGRAVOS E NOTIFICAÇÕES - SINAN (2019) Portal da saúde. DATASUS Web. Available in: <http:// www2.datasus.gov.br/DATASUS/index .php? area $=0203 \&$ id= 29878153>. Accessed 19 dec. 2019.

UBIRAJARA FILHO, C. R. C. et al. Lutzomyia evandroi in a new area of occurrence of leishmaniasis. Acta Parasitologica, v.65, p. 1-8, 2020.

WORLD HEALTH ORGANIZATION - WHO (2019) Leishmaniasis. World Health Organization Web. Available in:<https://www.who. int/en/news-room/fact-sheets/ detail/leishmaniasis $>$. Accessed 30 jun. 2019.

YARED, S. et al. Diversity and altitudinal distribution of phlebotomine sand flies (Diptera: Psychodidae) in visceral leishmaniasis endemic areas of northwest Ethiopia. Acta Tropica, v.176, p.1-10, 2017. 